\title{
(NE)OČEKIVANI OBRTI HIBRIDNOG IDENTITETA NA PRIMERU BRAĆE IKBAL U ROMANU BELI ZUBI ZEJDI SMIT $_{1}$
}

Prvi roman Zejdi Smit Beli zubi donosi priču o blizancima Madžidu i Milatu Ikbalu. Kao sinovi emigranata iz Bangladeša, braća su rano suočena sa teškim bremenom očekivanja roditelja, nasleđa i stvarnošću moderne Britanije. Ovaj rad ima za cilj da prikaže na koji način će hibridni identitet blizanaca imati očekivan odnosno neočekivan ishod sa stanovišta teorije i radnje. Koristeći građu koja je sadržana u samom romanu kao i teorije značajnih mislilaca u oblasti kolonijalnih i postkolonijalnih studija, ovo istražiivanje nastoji da pokaže da je sudbina blizanaca u velikoj meri očekivana iz ugla teorije, dok iz perspektive radnje to nije slučaj. Zaključeno je da blizanci predstavljaju dve strane postkolonijalnog iskustva koje se međusobno potiru, ali i ne postoje jedna bez druge. Ovaj rad takođe teži da otvori put novim istraživanjima koja nastoje da povežu ovaj roman sa najznačajnijim delima o hibridnom identitetu iz kolonijalnih i postkolonijalnih studija.

Ključne reči: Beli zubi, hibridni identitet, Madžid i Milat Ikbal, postkolonijalni subjekt, očekivano i neočekivano.

\section{Uvod}

Debitantski roman Zejdi Smit Beli zubi doživeo je veliki uspeh kako kod kritičara tako i kod publike. Ova povest o odrastanju u multikulturalnom Londonu obuhvata gotovo sve značajne teme savremene britanske proze, a odnos prema prošlosti kako kolonijalnoj i istorijskoj tako i onoj intimnijoj odnosno porodičnoj daje osnov za razumevanje čitavog dela. U duhu pisaca kao što su Nejpol, Ruždi i Kurejši, autorka se hrabro hvata u koštac sa istorijom i određivanjem identiteta onih koji su po rečima Karima Amira, protagoniste Bude iz predgrađa, „po rođenju i vaspitanju Englezi, zamalo” (Kurejši 2001: 7).

Univerzitet u Beogradu, Filološki fakultet, Studentski trg 3, 11000 Beograd; amitrovic2020@gmail.com

1 Ovaj rad predstavlja završno istraživanje iz predmeta Postkolonijalna književnost na engleskom jeziku i završen je pod mentorstvom prof. dr Aleksandre Jovanović. 
U mnoštvu likova koji se bore da svoj identitet odrede prema koordinatama bivše postojbine svojih roditelja, sada često samo izmaštanog toposa, ali i sadašnje domovine koja ih u velikoj meri oblikuje, izdvajaju se braća Ikbal. Jednojajčani blizanci rođeni sa malom vremenskom razlikom, Milat i Madžid, predstavljaju izuzetno poigravanje sa konvencionalnim idejama o hibridnom identitetu, a njihovo kompleksno sazrevanje i razvoj daju nov uvid za razmatranje čestih postkolonijalnih dilema.

Beli zubi koriste blizance kao staro književno sredstvo za ispitivanje ljudske sudbine, ali na svež način unose u blizanački mit nove teme modernog doba uspevajući da tako preokrenu stereotipni blizanački eksperiment i tradiciju (Švanebek 2020: 15). Pošto imaju isto genetsko nasleđe, ali različito odrastanje, blizanci u ovom romanu simbolišu i podeljeni kolonijalni identitet jer će jedan stvarati život na tlu bivše kolonije (u Bangladešu), dok će drugi imati priliku da se iskaže u samom srcu Imperije (Londonu). Primer blizanaca pokazuje paradoksalnu prirodu kolonijalne mimikrije jer je ona, prema Homiju Babi, uvek vođena suprotnim arhetipskim silama „narcisoidnosti i paranoje”, međutim upravo zbog tog nesklada ishod kolonijalnog identiteta nikada nije do kraja predvidljiv (Švanebek 2020: 17).

Kada se blizanačkoj enigmi doda sva složenost kolonijalne prošlosti i hibridne sadašnjosti, narativ o Milatu i Madžidu Ikblu postaje teren za ispitivanje očekivanog i neočekivanog. I kao što su sami blizanci fizički isti, ali karakterom drugačiji, tako i njiihovi životni putevi pokazuju sličnosti koje se ne mogu shvatiti bez razilaženja. Madžid se vraća iz Bangladeš kao ateista i budući pravnik iako poslat da postane pravi musliman, dok se Milat u Engleskoj, centru liberalnog individualizma i ljudskih sloboda, nakon prezasićenja plodovima neobuzdanog kapitalizma, transformiše u radikalnog pripadnika militantne islamske organizacije koja ključ uspešne političke borbe vidi u nasilju.

Koncept blizanaca u sebi sadrži spoj ambivalentnih karakteristika tako da oni kao stilsko oruđe gotovo uvek bude osećanje uznemirenja i preispitivanja poznatog usled očekivane međusobne sličnosti, ali i velike neočekivane različitosti (Švanebek 2020: 18). Analogno ovome, svaki modalitet kolonijalnog iskustva razlikuje se u odnosu na mnoge parametre (klasa, rod, kontinent, istorija), ali je i tajanstveno povezan tamnom niti prevlasti kolonizatora (Spivak 1991: 88). Zbog toga je priča o Madžidu i Milatu večna kolonijalna priča ispričana u novom ruhu, iz ugla teorije objašnjiva i očekivana, ali iz ugla radnje puna uzbudljivih previranja i skretanja. 


\section{Hibridni identitet kao ograničenje}

Za razumevanje muških protagonista druge generacije imigranata iz Bangladeša Milata i Madžida, centralno je pitanje hibridnog identiteta. Iako ovaj pojam deluje apstraktno, on mnogostruko utiče na očekivanost i neočekivanost sudbine blizanaca i neophodan je za analizu braće Ikbal.

Prema rečima Stjuarta Hola, hibridni identitet je koncept od ključnog značaja za budućnost velike Britanije, jer kultura koja je jednoobrazna i isključivo belačka nije dovoljna da zadovolji mnoge raznolike grupe koje trenutno žive u Kraljevini (2005: 77). Bogatstvo erudicije, relgije i tradicije ovih politički-nazvano manjinskih grupa izmiče znanju čak i najobrazovanijih kreatora društvene politike a to ovakve aktere neminovno smešta u sferu periferije ili senzacionalističke egzotike (2005: 80-82) i na taj način hibridni identitet postaje pre ograničenje za sopstvene nosioce nego proizvoljna odrednica.

Hol tvrdi da je takozvani „osnivački mit” narativ onih koji su kolonizovali prošlost i dali autoritet prosvetiteljskoj ideji opšte istine u tumačenju istorije (2005: 77). Međutim, oni koji nisu uklopljeni u tu shemu definisani su isključivo kao Drugo i oduzeta im je moć da predstavljaju sebe same (Hol 2005: 79). Takav odnos moći jeste glavni kamen spoticanja savremene Britanije u pronalasku društvene harmonije, a kako bi se on odstranio „osnivački mit mora se ponovo izmaštati ovoga puta sa ciljem da uključi sve stanovnike Velike Britanije" (Hol 2005: 84).

Iz primera braće Ikbal jasno je da hibridni identitet jeste stega na putu ka sazrevanju i punoći življenja jer ih on od detinjstva definiše kao drugačije u odnosu na normu i tera na borbu sa okolinom i sa sobom samima.

\section{Otac kao simbol porodične prošlosti}

Homi Baba tvrdi da postkolonijalno ne sadrži prefiks ,post” jer dolazi posle, odvojeno od onoga pre, već je to termin višeznačan u tome što podrazumeva prošlost kao kontekst za budućnost (Skvajers 2002: 44). Postkolonijalni subjekt dakle ne dolazi ex nihilo, spreman da popuni praznu stranu istorije, oslobođen stega starog i spreman da bezbrižno uplovi u novo. On je pod velikim uticajem prošlosti, a narator Belih zuba ne pokušava da nas obmane u tom pogledu jer već epigraf romana navodi citat iz Bure „ono što je prošlo je prolog” (Smit 2004: 7). 
Dve velike stare istorije jesu neizbežne, ali je privatna istorija ono čega blizanci neće moći da se oslobode. Njihovi roditelji, migranti prve generacije, imaju različite stavove prema asimilaciji tako da će manje progresivni roditelj, u ovom slučaju otac, biti prepreka obojici da sebe prihvate kao spoj raznolikih uticaja (Skvajers 2002: 30).

Otac blizanaca Samad u potpunosti odgovara Ruždijevom opisu imigranta iz Satanskih stihova. On je satkan od „ostataka duše, fragmentiranih sećanja, odbačenih kutaka, otkinutog maternjeg jezika, narušene intimnosti, neprevodivih šala, ugušene budućnosti, izgubljenih ljubavi i zaboravljenog značenja praznih, napadnih reči - otadžbina, pripadanje, dom" (Ruždi 2000: 6). U nemogućnosti da ode napred, stoji zauvek zaglavljen u međuprostoru, koji ne uspeva da izmiri na način koji bi ga učinio srećnim. Nekada student prestižnog univerziteta i budući intelektualac, u novoj zemlji ne uspeva da se istakne i radi kao konobar u restoranu svog rođaka Ardašira. Beg od problema traži u O'Konelovoj bilijarnici sa svojim najboljim prijateljem Arčijem, a sinovima postavlja striktne zahteve u pogledu očekivanja prema njihovom obrazovanju i životu što ga otuđuje od njih još u njihovom ranom detinjstvu.

Kroz Samadov lik parodira se hibridni identitet jer on pokazuje svu ironiju pokušaja suštinskog pomirenja načela Istoka i Zapada (Lipovšek 2015: 228). I zaista, on je rastrzan između ,vere i sekularizma, absolutizma i kompromisa” u trajnoj dilemi da li da odbaci grešne nagone ili podlegne iskušenju (Skvajers 2002: 30). Zbog toga se stalno poziva na dve maksime - „bezgrešnima je bezgrešno sve što čine” i „ne može se poštenije priznati” (Smit 2004: 132-134), ali, kao što to primećuje pronicljivi narator, islam nije religija gde se mogu sklapati dogovori sa Tvorcem (Smit 2004: 132), te Samadov pokušaj pronalaženja unutrašnjeg mira nikada ne nailazi na uspeh.

Za migrante prve generacije domovina često podsvesno predstavlja harmoničan sklad u koji se prebacuju neostvarene težnje, ideali i htenja (Ruždi 1991: 10), te i sam Samad, kako se radnja razvija, sve više biva opsednut idejom domovine koja će poput utopije njegovim sinovima pružiti korene, čvrstu osnovu bića, moralni kompas i spasenje duše.

\section{4. (Ne)očekivano detinjstvo}

Rođeni u porodici emigranata iz Bangladeša, Milat i Madžid svoj život počinju u severnom Londonu. Njihovi roditelji kao da dolaze iz nekog drugog sveta u odnosu na ostale jer su se venčali u sklopu ugovorenog braka, a njihov otac visoko vrednuje muslimanske vrednosti. 
Iako je ton romana šaljiv, a problemi se tretiraju sa izvesnom lakoćom (Tju 2013: 15), blizanci se od najranijeg detinjstva susreću sa različitim vidovima rasne netrpeljivosti. Prema rečima Radjarda Kiplinga „onaj ko se rano napio na izvoru razočarenja, to teško može potisnuti kasnije" (Tju 2013: 17), a blizanci su često žrtve predrasuda i nepovoljnog suda već samom svojom pojavom. Kada su u sklopu engleskog običaja Svetkovina žetve (Harvest Fest) odneli hranu jednom pukovniku u penziji, on je mislio da su prodavci, a zatim ih uvredio svojim pripovedanjem o ubijanju crnaca u Kongu kao i nepoverenjem u činjenicu da je njihov otac služio u britanskoj vojsci. Drugom prilikom jedan penzioner u autobusu tvrdio je kako bi ,svi oni trebalo da se vrate tamo otkuda (...)" međutim topot nogu prigušio je ,najstariju rečenicu na svetu” (Smit 2004: 156), a blizanci svojim mladalačkim duhom uspevaju da nadjačaju svest o svojoj drugosti (Skvajers 2002: 38).

Ukoliko pogledamo obimnu postkolonijalnu misao, doći ćemo do zaključka da je situacija na koju blizanci nailaze donekle očekivana. Fanon tvrdi da je identitet kolonijalnog subjekta ispisan na čitavom njegovom telu, odnosno da je njegova suština usisana i prebačena na ovu jednu karakteristiku (2008: 112). Po mišljenju Sezera, beli čovek će pri proceni drugog belog čoveka primeniti niz suptilnih kategorija, ali ukoliko dođe u susret sa nekim druge boje kože, on će pretpostaviti svoju etičku i gnoseološku superiornost (1972: 57). Dakle, kolonijalni subjekt će kao insekt biti izložen pogledu kolonizatora, seciran i zatvoren u međe svoje drugosti (Fanon 2008: 116).

Međutim, blizanci su sa jedne strane zbir starih istorija, krvavog kolonijalizma i imperijalizma, ali sa druge, oni su nova vrsta Britanaca kako bi to nazvao Hanif Kurejši. U svom eseju Znak duge, Kurejši tvrdi da deca koja su rođena u Engleskoj od roditelja stranog porekla nemaju gde da se vrate jer je Engleska zemlja njihovog rođenja i života (1986: 14). Mit o povratku na staro nemoguće je izvršiti, kao što je nemoguće poništiti vekove kolonijalne istorije. Britanci bi dakle trebalo da prihvate ovu novu hibridnu vrstu pre nego da zahtevaju radikalne promene društva (Kurejši 1986: 38).

Međutim, način na koji će se blizanci suočiti sa svojom drugošću neće biti do kraja predvidljiv jer sam roman slavi čovekovu slobodu izbora nasuprot unapred određenim kategorijama (Tju 2013: 16). I kao što miš kome je genetski predodređen svaki budući dan uspeva da pobegne kroz pukotine u zidu, tako i blizanci uspevaju da se probiju kroz složenu mrežu rasne i kolonijalne determinacije. 


\subsection{Nagli prekid}

Najznačajniji događaj koji će uticati na razvoj blizanaca je odluka njihovog oca Samada da ih razdvoji. Do ovog čudnog i naglog rastanka dolazi prvobitno usled Samadovog nezadovoljstva samim sobom, a radikalni potez da razdvoji blizance na koji se odlučio predstavlja pokušaj otkupljenja za sopstvene grehe. Svestan da pije, upušta se u vanbračnu avanturu i krši mnoge postulate islama, on postaje opsednut grižom savesti kao i idejom povratka korenima odnosno tradiciji.

A što je Samada plima dalje nosila i vukla u dubine uz pomoć primamljive sirene po imenu Popi Bart-Džons, on je postajao odlučniji da stvori korene svojim sinovima na obali; duboke korene koje nikakva oluja niti bura ne mogu iščupati. (Smit 2004: 183)

On takođe delom zaista veruje da će, kroz transcendentno, njegova deca dostići viši nivo spokoja od svojih sekularno vaspitanih vršnjaka. Prema rečima Ruždija, ortodoksni muslimani ne mogu da pojme etički relativizam Zapada u kome norme nisu zadate unapred, mogu se kršiti, menjati i stalno revidirati bez većih posledica (1991: 384). Samad, naviknut na sistem vrednosti koji od čoveka ne traži stalnu i nepresušnu potragu za odgovorima koja u periodu postreligije često ostaje jalova ili nezadovoljavajuća, smatra da je Zapad iskvaren i licemeran u svojoj nemogućnosti da sagleda svet pravim očima i neadekvatan kao okruženje za duhovni rast.

Zbog svega toga, šalje blizanca koji je više nadaren za školu Madžida svojim roditeljima u Bangladeš. Međutim, ovaj naizgled jasan eksperiment poprimiće razmere farse, neočekivanih obrta i začuđujućih ishoda, jer će se želje i ideje Samada sudariti sa htenjima samog Madžida.

\section{Madžid}

Ukoliko se Madžid analizira iz ugla teorije Franca Fanona, može se reći da on želi da stavi belu masku odnosno da pokuša da premosti večito nerazrešivi jaz između kolonizatora i kolonizovanih. Kako Fanon kaže u svom delu Crna koža, bele maske, „nije stepen razvoja, civilizacijskog ili mentalnog, ono što vodi do podvojenosti ili osećaja inferiornosti kolonijalnog subjekta, već je u pitanju shema moći koja je duboko ukorenjena u shvatanjima obe strane" (2008: 22). Kolonizator ne postoji bez kolonizovanog, kao ni obratno, ali je jasno da prvi termin uvek implicira viši stepen moći od drugog. Zbog toga je jedna od očekivanih 
reakcija kolonizovanog želja za približavanjem uzoru iz kolonijalne paradigme (Fanon 2008: 42), kao što je to slučaj sa Madžidom.

Još otkada je svojim prijateljima sa šaha rekao da se zove Mark Smit, ovaj pametni lik pokazao je veliku sklonost ka asimilaciji i težnju da bude prihvaćen od strane engleskog okruženja. Kako sam narator kaže, to je „samo bio simptom dubljeg oboljenja jer je Madžid zaista želeo da pripada nekoj drugoj porodici”.

Hteo je da gaji mačke umesto bubašvaba, da mu majka svira na violončelu, umesto što zuji za šivaćom mašinom, želeo je da se na jednu stranu njihove kuće naslanjaju drvene letvice po kojima raste cveće, umesto gomile tuđeg đubreta, da u predsoblju stoji klavir a ne polomljena automobilska vrata njihovog rođaka Kuršeda, voleo bi da biciklom ode na raspust $\mathrm{u}$ Francusku, umesto što odlazi na jednodnevne izlete do Blekpula u posetu tetkama... Žalio je što mu otac nije lekar, već jednoruki konobar. (Smit 2004: 145)

Madžid se rađe krije u dosadnoj predvidljivosti običnog, prozaičnog engleskog imena kao što je Mark Smit, nego što želi da se obračuna sa svojim isprepletenim korenima (Skvajers 2002: 32). Prema rečima Anije Lumbe, kolonijalni subjekt stvoren je sa idejom da uvek bude svestan svog nedostatka u odnosu na uzor, da uvek teži da ga dostigne i da nikada za baš to malo ne uspe (2005: 194). Sa ovim se slaže i Fanon koji tvrdi da su onom postkolonijalnom subjektu koji još uvek veruje da može poboljšati svoje izglede asimilacijom, mimikrija i imitacija prva sredstva samoodbrane (2005: 47).

Iako je njegov otac zacrtao religiju kao pravi put za njega, Madžid je inspirisan idejama prosvetiteljstva i racionalizma, odnosno načinima razmišljanja na kojima se bazira zapadna civilizacija. Misticizam i idealizam islama nemaju uticaja na mladića koji svet još od malih nogu posmatra kroz oči nauke, te nadanja njegovog oca, da će ga boravak u svetu punom izazova očvrstiti i okrenuti religiji, ostaju neispunjena. Madžid je izvrtanje starog narativa o kolonijalnom subjektu koji uz ogroman trud sve više liči na kolonizatora i ostavlja svoj način razmišljanja zarad stranog odnosno kolonizatorskog (Skvajers 2002: 34). U njegovom slučaju, on bez ikakvog truda liči na kolonizatora, a uprkos ogromnom naporu porodice da ga vrate tradiciji, ostaje dosledan svom primarnom ja.

Iako je od odlaska u domu Ikbalovih postao neka vrsta totema i božanstva kome se svi dive, ali koji to divljenje ne može ni da opravda ni da ospori (Skvajers 2002: 33), Madžid se neće pokolebati u svojoj težnji da doprinese nauci. Nakon korespondencije sa Markusom Čalfenom, on odlučuje da se vrati u Englesku na studije prava i da pravno zastupa svog uzora u projektu Miš budućnosti koji je zbog svoje etičke potke izazvao mnogo kontroverze u društvu. 
Naime, Čalfen, čiji je mentor nacistički eugeničar dr Bolest, uspeva da promeni genetski kod jednog običnog miša putem bioinženjerstva u nadi da će takvim ogledom ući u trag načinu na koji se genetika može modifikovati kako bi se izbegla oboljenja kod ljudi. Madžid pozdravlja ovakav racionalni pokušaj da se ukroti i izmeni priroda koja je nesavršena, jer je on simbol i izdanak neumoljive prosvetiteljske misli koja stoji iza čitave zapadne nauke i koja ne prihvata ograničenja. Sa druge strane, Samad je vernik koji svoje shvatanje sveta zasniva na pokori prema Demijurgu, višem principu koji je prvi u hijerarhiji svih principa i čije se stvaranje ne popravlja i ne dorađuje jer to je akt najviše apostasije i svetogrđa.

Madžid povratnik nije samo željan novih vrata znanja, on je i veći Englez od Engleza (Smit 2004: 377). Obučen elegantno od glave do pete, sa savršenim akcentom engleskih obrazovanih viših klasa, bogatim fondom reči i hirurški preciznim umom, on više podseća na Dejvida Nivena nego na mladića koji je izbegavao prirodne nepogode i društveno-religijske nemire u zemlji na stalnom rubu opasnosti (Smit 2004: 393).

Samim tim, neizbežan je sukob između oca i sina koji će kulminirati u naizgled banalnom incidentu. Ako materijalni fenomeni kao što su hrana i odeća mogu biti markeri pripadnosti na isti način na koji to mogu metafizički kao što je religija (Lipovšek 2015: 247), onda je sendvič sa svinjetinom simbol nepovratnog prelaska u englesko iskustvo. Madžid ga poručuje uprkos razjarenom ocu i time mu suptilno poručuje da je era njegove vlasti završena.

Naivno je pretpostaviti da Madžid to radi usled svog nedostatka socijalne inteligencije (Tju 2013: 14). Nasuprot tome, njegova je inteligencija izrazito visoka, te je i način obračuna uvijen i višeslojan. Kao što je Ruždi primetio u svom eseju $S$ verom u boga, za ateistu sam sendvič jeste gubitak muslimanskog raja punog blagodeti i nežnih devojaka, ali je i osvajanje jednog novog prostora, a to je prostor slobode (1991: 377). Za samog Madžida sendvič jeste raskid sa bogom ali i značajno više sa Samadom.

Madžid je neočekivan sa stanovišta radnje za one kritičare koji veruju u aristotelovsku kauzalnost i verodostojnost, ali u beketovski postmodernoj metropoli uz osvrt na postkolonijalnu literaturu, njegov razvoj je i više nego očekivan. Prema psihoanalitičkoj misli, ono što najviše želimo da potisnemo neminovno će naći način da se vrati u naš život, pa je tako i Samadova ideja da se Zapad može odstraniti onda kada je već tu bila osuđena na propast od samog početka.

Na kraju krajeva, trauma je nešto što ljudi stalno ponavljaju uprkos svemu i u tome je ležala tragedija Ikbalovih. Oni nikada nisu prestajali da ponovo proživljavaju 
davnašnje bekstvo iz jedne u drugu zemlju, iz jedne u drugu veru, iz nekadašnje otadžbine u blede, pegave ruke druge vladarke. (Smit 2004: 155)

\section{Milat}

U svom uticajnom eseju Mogu li podređeni da govore, Spivakova je postavila iskonsko pitanje o mogućnosti glasa kod ugnjetavanih društvenih grupa. Kolonizovani su podređeni po samoj prirodi kolonijalnog odnosa, pa samim tim iz njihove podređenosti izrasta problem autentičnog glasa (Spivak 1991: 85). Da li kolonizovani uvek pokušavaju da se izraze glasom koji im je namenio model kolonizatora? Primer drugog blizanca Milata pokazuje da to nije slučaj.

Za razliku od starijeg blizanca, Milat je uvek bio ,sinonim za nevolje. Kao društveni kameleon posedovao je onu lakoću uklapanja koja dolazi ljudima koji ne pripadaju nigde" i rano je postao predvodnik različitih društvenih grupa (Smit 2004: 206). Inspiraciju nalazi u gangsterskim filmovima poput Kuma koji su za njega najviša ostvarenja estetike u umetnosti.

U njima je Milat saznao nešto o pravim očevima, glavama porodice. O kumovima, pobratimima, tipovima kao iz uloga Paćina i De Nira, o muškarcima u crnim odelima, koji dobro izgledaju, brzo pričaju i nikada ne čekaju da dobiju (onaj prokleti) sto, o ljudima sa dve zdrave ruke, brze na oružju. (Smit 2004: 206)

Međutim, ova opsesija jednim aspektom kulture kolonizatora odnosno jednim sistemom vrednosti biće ponovo ,samo simptom dubljeg oboljenja” (Smit 2004: 145), jer kada se promeni predmet obožavanja, Milat će lako preći na religiozni fundamentalizam. Može se reći da je on kolonijalni subjekt koji je zbunjen, ostavljen u procepu stalnih sumnji koje ne može da razreši jer ne ume da internalizuje kolonijalni sistem vrednosti do kraja.

Asimilacija podrazumeva izbor, želju da se odbaci određeni ideal zarad prihvatanja drugog, svestan napor učinjen sa mišlju da je pronađen etički model kome treba težiti (Baba 1994: 66). Međutim, Milat je ostao zauvek zaglavljen u međuprostoru (Smit 2004: 208) i za njega nije bilo moguće da kolonijalnu dilemu razreši racionalno na način na koji je to učinio njegov brat.

On je, poput podvojene ličnosti, stajao jednom nogom u Bangladešu, a drugom u Vilzdenu. U glavi se nalazio podjednako tamo i ovde. Nije mu bio potreban pasoš da bi živeo na dva mesta odjednom, niti viza da bi živeo svojim i bratovljevim životom. (Smit 2004: 208) 
Prema rečima Franca Fanona, ukoliko kolonijalni subjekt prepozna mrežu laži koja je ispletena oko njegovog stanja i ukoliko shvati da je obmanut, postaje besan (2005: 106). Doktrine o obrazovanju, humanitarnoj osnovi kolonijalne misije, nazadnosti i primitivnosti duha kolonizovanog u odnosu na suštinu bića kolonizatora, rasprše se onda kada kolonijalni subjekt shvati ekonomsku stvarnost svoje situacije (Sezer 1972: 11). Slično tome, Milat je bio svestan da će ga uvek smatrati Pakistancem koji miriše na kari, bez obzira na to gde se rodio; da nema seksualni identitet; da se veruje kako on otima posao drugima ili je nezaposlen, pa prima milostinju od države; ili je pozapošljavao silnu rodbinu; da može da postane zubar, ili da otvori sopstvenu radnju i prodaje kari; ali, nikada ne može da postane fudbaler ili režiser; da govore kako bi trebalo da se vrati u sopstvenu zemlju; ili da samog sebe izdržava, kad već sedi ovde; veruju da se klanja slonovima; kao i da nosi turban; a niko, ko izgleda, govori ili se oseća kao Milat, ne može da dospe na naslovne strane, osim ako ga ucmekaju. Ukratko, ne predstavlja nikog i ništa u ovoj zemlji i njegov glas ne može da se čuje. (Smit 2004: 221)

Zbog svih ovih faktora, postaje besan i neprijateljski nastrojen prema kulturi u kojoj je rastao. Prema Fanonu, čitav sistem kolonijalne eksploatacije počiva na verovanju koje je usađeno u um kolonizovanog; on je životinja i ova se poruka kroz kolonijalno nasilje stalno ponavlja dok kolonijalizovani i sam ne počne u to da veruje (2005: 94). Međutim, ukoliko on shvati da je ipak čovek jedini odgovor koji će potražiti za svoj problem, ležaće u nasilju. To nasilje nikako nije moralno opravdano, ali jeste posledica mentalnih stanja koje dug period podređenosti i kolonijalizma budi kod kolonizovanog subjekta (Fanon 2005: 40).

Milat će prvobitno pokušati da spali „bogohulnu knjigu”² koju nije čitao niti zna išta o autoru s ciljem da razreši enigmu svog pripadanja i zauvek raskrsti sa engleskom kulturom (Skvajers 2002: 39). Međutim, kada se veliki broj muslimana, uključujući i njegovu majku, dâ u odbranu ove knjige, shvatiće da ni sada neće moći da preseče i ostavi teret prošlosti iza sebe.

Prema rečima Ruždija, religija i politika (kolonijalna, kao i svaka druga) predstavljaju odraz čovekovog najdubljeg nagona, a to je nagon za snovima (1991: 377). Kada jedan san ne uspe, čovek ga menja drugim jer ne može drugačije osim da svet vidi kroz veo sopstvenog očekivanja. Zbog toga, neuspele postkolonijalne politike često vode u religiozni fundamentalizam. Raj na zemlji koji se pretvara u noćnu moru mora biti zamenjen večnim rajem u koji se još niko nije razočarao jer nije preživeo da o tome govori (Ruždi 1991: 378- 381).

2 Referenca na Satanske stihove S. Ruždija. 
Slično tome, Milat prelazi iz sekularnog u religiozni san (Skvajers 2002: 42). Kada uprkos želji da bude vođa bande, shvati da ni prema talentima i mogućnostima, ni prema dubini veze koju ostvaruje sa drugim likovima, ne može da ostvari ovaj cilj, počinje da se interesuje za aktivnosti radikalne muslimanske organizacije koja dejstvuje pod akronimom KEVIN ${ }^{3}$.

Fundamentalizam je često pribežište zbunjenih, pa i Milatu deluje da je konačno pronašao istinu za kojom je tragao svih prethodnih godina. Prema Ruždiju, povratak religije na Zapadu označava pad poverenja u nacionalnu državu (koliko god ove dve sile bile povezane kroz istoriju), a za Milata upliv u veru slično tome označava raskol sa Imperijom i njenim nasleđem (1991: 381).

Čitajući mnogobrojne pamflete svoje organizacije, Milat počinje da u svoj život uvodi protokol strogih molitvi, ostavlja supstance koje je konzumirao i ne učestvuje više u bludnim ili erotskim aktivnostima. Prema rečima Filipa Tjua, Zejdi Smit je ovim otvorila Pandorinu kutiju jer je postavila pitanje granice između „filozofske religije i pukog fundamentalizma, pokreta i pravih verovanja, principa i onoga na šta se oni svode u surovoj društvenoj stvarnosti” (2013: 20).

U svom eseju Pol i sekularizam, Hanif Kurejši tvrdi da je pojava novog islamskog fundamentalizma među pripadnicima dijaspore u Engleskoj posledica razbijanja starih struktura, odnosno narativa koji, pošto su ostavili toliko pitanja bez jasnog odgovora, moraju biti zamenjeni strogim sistemom u kome se niko više neće usuditi da ih postavlja (Čeri 2021: 36). Prema Dejvu Ganingu, primer Milata i sličnih književnih likova predstavlja radikalni odgovor odnosno bunt protiv norme belačkog, engleskog društva koje je ove mladiće ostavilo na margini i suočilo sa rasizmom (Čeri 2021:38).

Međutim, hibridni identitet ostaje prisutan koliko god subjekt želeo da ga se oslobodi jer su duboko ukorenjene strukture često nasleđene ili u domenu nesvesnog, pa ih je samim tim teško kontrolisati (Lumba 2005: 145). Kao što je Gandi koristio najviše domete zapadne filozofije u svojoj borbi protiv Engleza (Lumba 2005: 145), tako i Milat u borbi protiv, po svom mišljenju, iskvarenog zapadnjačkog društva koristi moto preuzet iz gangsterskog filma Badfellas koji modifikuje za svoje potrebe. „Novi” Milat repliku „od kad znam za sebe oduvek sam želeo da budem gangster” menja u „od kad znam za sebe oduvek sam želeo da budem musliman" (Smit 2004: 413) i time nenamerno pokazuje da će deo engleskog nasleđa zauvek ostati zaglavljen u njemu koliko god mu se on suprotstavljao.

Kulminacija Milatove borbe dešava se na predstavljanju projekta Miš budućnosti, na kome njegov brat učestvuje kao predstavnik glavnog naučnika. Milat

3 Skraćeno od naziva Keepers of the Eternal and Victorious Islamic Nation, prevedeno kao Čuvari večne i pobedonosne islamske nacije (Smit 2004: 277). 
je nezadovoljan što su se svi pripadnici KEVIN-a opredelili za nenasilne vidove protesta, te on sam vadi pištolj i puca u jednog od idejnih tvoraca. Milat nije uspeo da odgovori na prinudnu asimilaciju, te mu se nasilje čini kao neizbežan vid samoodržanja. On takođe kroz nasilje želi da povrati svoj identitet jačine, muškosti i nezavisnosti koju su mu predrasude zbog porekla oduzele (Čeri 2021: 40). On više nije samo jedan Paki koga mogu da stavljaju u kutije i maltretiraju, on je sada pretnja i izvor straha za kolonizatora.

Međutim, nasilje ne može trajno da zatvori jaz identiteta, te će Milat na prinudnom radu koji mu je sud propisao zbog ovog napada početi da uviđa da je njegova drugarica Ajra bila u pravu kada je rekla da u Engleskoj dolazi „novo vreme, ne tako daleko, kada koreni više neće biti važni, jer ne mogu, jer ne smeju, jer su preduboki, jer su previše upetljani, jer su upravo đavolski duboko zakopani" (Smit 2004: 484).

\section{Problem naratorovog glasa}

Na kraju značajno je spomenuti da vid naracije predstavlja još jednu oblast za razmatranje postkolonijalnog iskustva. Beli zubi, generalno sagledano, jesu istorijski roman koji sjedinjuje priče tri savremene engleske porodice (Skvajers 2002: 66), međutim, Smitova koristi širok spektar stilskih sredstava kako bi fabulu približila čitaocima. Pored reminiscencija iz prošlosti, fragmentiranih dijaloga i kakofonije mnogostrukih glasova, sveznajući narator kroz prizmu svog shvatanja sveta pripoveda o događajima u modernom Londonu.

Ovakvo pripovedanje ne samo da problematizuje formu i uspostavlja otklon od realističkog privida stvarnosti (Skvajers 2002: 67), već stavlja u pitanje i vrednosne sudove koji proizilaze iz strukture dela. Narator, kome se ne može do kraja verovati, sadrži u sebi i ironijski osvrt na kolonijalnog tvorca, a njegov problematizovan glas predstavlja eho kojim se podvlači kompleksnost postkolonijalnog iskustva.

U svetlu ovakvog zaključka, Madžid i Milat se mogu shvatiti kao likovi koji izmiču fiksiranom mestu koje im je namenila postkolonijalna teorija (iako na mnogo načina jesu povezani sa njom) i samim tim pokazuju virtuoznost autora.

\section{Zaključak}

Prema rečima Karela Filipsa, želja za pripadanjem u Belim zubima nije farsična već bolna; „Beli zubi su puni grimasa i lažnih osmeha kao i maski koje likovi stalno navlače da bolje sakriju svoju patnju. Hibridna nacija, kao što je savremena 
Britanija, i dalje sa teškoćom gleda u ogledalo i prihvata veliku različitost i bol koja uvek prati takve promene u biti stvari” (Skvajers 2002: 380).

Madžid i Milat Ikbal stoje kao alegorije u centru bola, koji nikada nije do kraja objašnjiv, ali je uvek prisutan u formiranju očekivanog i neočekivanog. Hibridni identitet sa stanovišta teorije ima nazgled jasne ishode, ali kada se pogleda kroz prizmu radnje, on se osipa jer čovek dolazi do svoje pune kontradiktornosti, a blizanci otvaraju pitanja do kojih nikada neće voditi potpuni odgovori. Kao što ,prošlost nikada nije samo nezgodna, a budućnost samo savršena" (Smit 2004: 497), tako blizanci čitaoca ostavljaju u razmišljanju o budućnosti kolonijalnih odnosa u svetu u kome su se ose moći pomerile, a kolonijalizam promenio svoje lice.

Kako sam narator poručuje, „kraj je uvek zapravo samo početak neke još duže priče" (Smit 2004: 496), pa tako i trajna vrednost ovog romana leži upravo u tome što se može tumačiti iz mnogo uglova. Autorkina sposobnost da sagleda stanovište kolonijalnog subjekta više je nego značajna danas kada je iskrena književnost kod Ruždija predstavljena kao soba sa mnogo različitih glasova, sve više ugrožena radikalnim pokretima i pojednostavljenim tumačenjima.

\section{LITERATURA}

\section{Primarna literatura}

Kurejši 2001: H. Kurejši, Buda iz predgrađa. Prevod: Đorđe Tomić. Beograd: Plato.

Smit 2004: Z. Smit, Beli zubi. Prevod: Zorica Smederevac. Beograd: Narodna knjiga.

\section{Sekundarna literatura}

Baba 1994: H.K. Bhabha, The location of culture. London/New York: Routledge.

Čeri 2021: P. Cherry, Muslim masculinities in literature and film: Transcultural identity and migration in Britain. London: Bloomsbury Publishing.

Fanon 2005: F. Fanon, The wretched of the Earth. New York: Grove Press. Fanon 2008: F. Fanon, Black skin, white masks. New York: Grove Press. Hol 2005: S. Hall, Whose heritage? Un-settling 'the heritage', re-imaging the post nation. In R. Araeen, S. Cubitt, \& Z. Sardar (eds.), The Third text reader on art, culture and theory, London: Continuum, 21-31. 
Kurejši 1986: H. Kureishi, My beautiful laundrette and the rainbow sign. London: Faber \& Faber Limited.

Lipovšek 2015: E. Lipovšek, Grad i identitet: Postkolonijalni London. Doktorska disertacija. Filološki fakultet Univerziteta u Beogradu.

Lumba 2005: A. Loomba, Colonialism/Postcolonialism. London/New York: Routledge.

Ruždi 1991: S. Rushdie, Imaginary homelands. London: Vintage Books.

Sezer 1972: A. Césaire, Discourse on colonialism. New York: Monthly Review Press.

Skvajers 2002: C. Squires, Zadie Smith's White teeth. London: Bloomsbury Publishing.

Spivak 1991: G.C. Spivak, Can the subaltern speak. Basingstoke: Macmillan. Švanebek 2020: W. Schwanebeck, Literary twinship from Shakespeare to the age of cloning. New York: Routledge.

Tju 2013: P. Tew, Reading Zadie Smith: The first decade and beyond. London: Bloomsbury Academic. 


\title{
Ana Mitrović
}

\section{(UN)EXPECTED TWISTS OF HYBRID IDENTITY AS MIRRORED IN THE EXAMPLE OF IQBAL BROTHERS IN THE NOVEL WHITE TEETH BY ZADIE SMITH}

\begin{abstract}
Summary
Zadie Smith's first novel White teeth tells a story about twins Magid and Millat Iqbal. Born into a family of Bangladeshi migrants, from an early age the brothers are faced with a heavy burden of their parents' expectations, legacy, and the reality of contemporary Britain. This paper sets out to show how the hybrid identity of the twins will evolve in an expected way from the point of view of theory and, conversely, how it will be unexpected from the perspective of the novel's plot. Using text evidence contained in the novel, as well as theories of significant thinkers from the sphere of colonial and postcolonial studies, this research aims to prove that the destiny of the twins was expected from the prism of theory, but unexpected if plot is taken into consideration. This paper suggests in conclusion that the twins represent two sides of postcolonial experience which complement and obliterate each other simultaneously. This research also aims to open the space for more studies conducted with a view to examining this novel and connecting it with most important works on hybrid identity from the area of colonial and postcolonial studies.
\end{abstract}

Keywords: White teeth, hybrid identity, Magid and Millat Iqbal, postcolonial subject, the expected and the unexpected. 


\title{
Ana Mitrović
}

\section{GLI (IN)ATTESI COLPI DI SCENA DELL'IDENTITÀ IBRIDA SULL'ESEMPIO DEI FRATELLI IQBAL NEL ROMANZO DENTI BIANCHI DI ZADIE SMITH}

\begin{abstract}
Riassunto
Denti Bianchi, il primo romanzo di Zadie Smith, ci porta la soria dei gemelli Majid e Milat Iqbal. Essendo figli di immigrati bangladesi, i fratelli sono già presto confrontati con l'onere pesante delle speranze dei genitori, del patrimonio e della realtà della Bretagna moderna. Questa tesina ha lo scopo di mostrare le maniere in cui l'identità ibrida dei gemelli avrà un colpo di scena atteso, ovvero inatteso, dal punto di vista della teoria e della trama. Usando la costruzione presente nel romanzo stesso oltre alle teorie di intellettuali notevoli nel campo degli studi coloniali e postcoloniali, questa ricerca ha l'intenzione di mostrare che la sorte dei gemelli è in gran parte attesa dal punto di vista della teoria, mentre questo non avviene dal punto di vista della trama. È concluso che i gemelli rappresentano due facce dell'esperienza postcoloniale, le quali si annientano, ma non esistono l'uno senza l'altro. Questa tesina ha anche lo scopo di aprire la strada a nuove ricerche che hanno l'intenzione di collegare questo romanzo con le opere più importanti dell'identità ibrida dagli studi coloniali e postcoloniali.
\end{abstract}

Parole chiave: Denti Bianchi, identità ibrida, Majid e Milat Iqbal, il soggetto postcoloniale, l'atteso e l'inatteso. 